\title{
Algunas cuestiones en torno a la recepción de las obras y servicios de urbanización por las entidades locales en los sistemas de gestión de base privada, a partir de la jurisprudencia contencioso-administrativa
}

\author{
Fernando E. Fonseca Ferrandis \\ Profesor Titular de Derecho Administrativo \\ Universidad Carlos III de Madrid
}

\begin{abstract}
SUMARIO: I. PLANTEAMIENTO DE LA CUESTIÓN. II. MARCO NORMATIVO APLICABLE; ALCANCE DE LA RELACIÓN PROPIETARIO PROMOTOR/ADMINISTRACIÓN ACTUANTE. III. ELEMENTO SUBJETIVO. IV. ELEMENTO OBJETIVO. V. VERIFICACIÓN DE LAS OBRAS Y SERVICIOS POR PARTE DE LA ADMINISTRACIÓN ACTUANTE; SUBSANACIÓN DE VICIOS O DEFECTOS. a) Ejecución total de la urbanización. b) Conformidad con el Plan o Proyecto de urbanización, corrección de su ejecución y su buen estado de conservación. VI. LA RECEPCIÓN; SUSCRIPCIÓN DEL ACTA DE RECEPCIÓN POR PARTE DEL PROMOTOR Y DE LA ADMINISTRACIÓN ACTUANTE. VII. CONSECUENCIAS DE LA RECEPCIÓN; LA TRANSMISIÓN DEL DEBER DE CONSERVACIÓN.
\end{abstract}

\section{PLANTEAMIENTO DE LA CUESTIÓN}

Como es conocido, la dinámica del proceso de urbanización supone que una vez ejecutadas las obras de urbanización y establecidos los servicios correspondientes, unas y otros deben ser cedidos al Ayuntamiento respectivo que, en principio, debe proceder a su recepción. Por tal acción entendemos el acto formal de aceptación por parte de dicha Administración local de las obras y servicios que, ejecutadas de acuerdo con las previsiones de un Proyecto de urbanización, deben ser objeto de cesión obligatoria y gratuita, de acuerdo con el planeamiento vigente.

Dicho así, a pesar de la aparente sencillez del tema, es lo cierto, sin embargo, que la praxis administrativa demuestra que la verificación de este trámite es una de las cuestiones que más conflictos y controversias suscita en el ámbito urbanístico. Simplificando las cosas es posible reconducir tal circunstancia, por un lado, a una falta de voluntad municipal por asumir el coste económico que puede implicar la recepción de aquellas obras y servicios, ignorando que, normalmente, son consecuencia de actos municipales previos que permitieron el desarrollo y ejecución de la urbanización y que 
si frecuentemente las dotaciones y servicios ejecutados no responden a las exigencias determinadas por el planeamiento o carecen de la calidad o aptitud suficiente para el cumplimiento de su destino urbanístico - circunstancias ambas que normalmente fundamentan la negativa municipal-, es debido habitualmente a la dejación municipal de sus funciones de control e inspección en relación con la tarea urbanizadora. En otras ocasiones, entran en juego los propios intereses particulares que, por diferentes motivos - algunos no confesables-, pretenden perpetuarse al frente de la entidad. En cualquier caso, el resultado de todo ello es por todos conocido: la existencia de unas urbanizaciones mal dotadas, carentes de los servicios que la vida moderna demanda o, simplemente, su abandono.

En el presente estudio se trata de analizar tan sólo una parte de la compleja problemática que plantea esta cuestión. Se trata de la posición mantenida al respecto por la jurisprudencia contencioso-administrativa que, ante el desfallecimiento de la legislación urbanística en su intento de dar respuesta a los numerosos interrogantes planteados, se ha erigido en un elemento jurídico de importancia trascendental dando lugar a un cuerpo jurídico de especial relieve.

\section{MARCO NORMATIVO APLICABLE; ALCANCE DE LA RELACIÓN PROPIETARIO-PROMOTOR/ADMINISTRACIÓN ACTUANTE}

Generalmente, las actitudes dirigidas a dificultar, dilatar o impedir indebidamente el desarrollo del proceso de recepción de las obras y servicios de urbanización, ya sea por parte de la Administración municipal, ya sea por parte de otros sujetos interesados en el mantenimiento de la situación existente, se fundamentan, todavía hoy, en una pretendida insuficiencia de la regulación vigente al respecto. Se olvida con ello que el procedimiento de recepción de las obras de urbanización aparece expresamente regulado en el artículo 180 del Real Decreto 3288/1978, de 25 de agosto, por el que se aprueba el Reglamento de Gestión Urbanística —en adelante, RGUcuya regulación proviene, a su vez, del antiguo artículo 10 del Decreto de 30 de junio de 1966 por el que se regulaban los beneficios tributarios previstos en la Ley del Suelo. Además, gran parte de las diferentes iniciativas legislativas autonómicas producidas en estos últimos años han abordado, si bien, con diferente alcance y pretensión este problema ${ }^{1}$.

\footnotetext{
${ }^{1}$ Así, las Comunidades Autónomas de Andalucía, Asturias, Baleares, Canarias, Castilla-La Mancha, Cataluña, Extremadura, La Rioja, Madrid, Murcia y Valencia cuentan con normativa propia,
} 
Es preciso destacar que la regulación de esta cuestión puede contar, además, con el fundamento legal que proporciona una específica regulación legal de carácter administrativo, integrada tanto por la Ley 30/1992, de 26 de noviembre, de Régimen Jurídico de las Administraciones Públicas y del Procedimiento Administrativo Común —en adelante, LRJAP y PAC - como, en su caso, por el Real Decreto Legislativo 2/2000, de 16 de junio, por el que se aprueba el Texto Refundido de la Ley de Contratos de las Administraciones —en adelante, TRCA—, legislación que permite salvar las importantes lagunas que, ni el precepto reglamentario citado - en su aplicación supletoria-, ni la normativa autonómica vigente —allá donde exista—, permiten afrontar. Recuérdese que se trata de textos legales que, además de vincular al legislador sectorial autonómico —o, en su caso, a la Administración de tal naturaleza territorial en el ejercicio de su potestad reglamentaria si, como ocurre en Baleares o Cataluña, tal cuestión es regulada a través de normas reglamentarias-, dado su carácter básico, obligan a su consideración a todo operador jurídico en su labor de integración del ordenamiento jurídico aplicable, pues en tanto legislación de carácter horizontal, articulan la totalidad del giro administrativo. Y no se olvide al respecto que el propio artículo 120. b) TRCA califica expresamente como contratos de obras públicas, entre otros supuestos, los que tengan por objeto actuaciones urbanísticas.

Pues bien, siendo dicha posición correcta como punto de partida, es preciso destacar que la concreta articulación de los dos textos legales citados en el procedimiento de recepción de obras y servicios de urbanización merece, no obstante, una mayor atención. En efecto, la aplicación de la legislación reguladora de la contratación administrativa al caso que nos ocupa se realiza, frecuentemente, de forma automática sin que el operador jurídico repare en la clase de relación establecida entre el promotor (Junta de compensación) y la Administración actuante cuando la aplicación de dicha legislación contractual está lógicamente limitada de acuerdo con su ámbito material de aplicación que, necesariamente, presupone la existencia de una relación de tal clase. En otras palabras; la aplicación del vigente TRCA al proceso de recepción de obras de urbanización procede si se acepta que la relación entre Junta de Compensación y Administración actuante tiene naturaleza contractual.

Dos son los fundamentos que pueden conducir a afirmar tal relación. Por un lado, la concepción de la Junta de Compensación como un «cuasi contratista» de la Administración actuante, de tal forma que entre ellos se

reguladora del procedimiento de recepción de estas obras. Por el contrario, Aragón, Cantabria, Castilla y León, Galicia, Navarra y País Vasco han guardado silencio al respecto. 
establece una relación de tal naturaleza jurídica, calificada expresamente en sede doctrinal como concesional ${ }^{2}$, calificación que, por lo demás, parece chocar con la concepción tradicional del derecho al desarrollo urbanístico y edificatorio que se vincula, como dimanación del mismo, con la propiedad del suelo y no a un eventual acuerdo con u otorgamiento de la Administración actuante que es justamente la idea que subyace al concepto de concesión. Por otro, en la consideración de las obras de urbanización como una obra pública, posición que, por el contrario, no ofrece ninguna duda pero que viene a reafirmar la idea anterior. De esta forma, la consecuencia lógica de que una Administración local «contrate» con una Junta de compensación la ejecución de una determinada obra pública (obras y servicios de urbanización) es la sujeción de dicha relación a la legislación de contratos de las administraciones a lo largo de todo el desarrollo de la misma

Es preciso destacar que tal concepción subyace en la propia jurisprudencia contencioso-administrativa, especialmente, cuando en el litigio se plantean cuestiones relacionadas con la verificación de los trámites de ofrecimiento y recepción de aquellas obras. De ahí que, aunque el Tribunal Supremo halla matizado la aplicación automática e irreflexiva de aquella legislación contractual al caso que nos ocupa, afirmando expresamente en relación con el trámite de recepción de las obras de urbanización que «...no puede aplicarse sin más el bloque normativo previsto para los contratos de obras públicas» (S. de 28 de enero de 1992 —aceptando la sentencia apelada—. Ponente: Magistrado Esteban Alamo -Ar. 1992/754-), acepte sin embargo, unánimemente y sin reservas, la existencia de una recepción meramente provisional previa a la definitiva, durante la cual, a modo de periodo de garantía, la Administración actuante puede imputar a la Junta de compensación las consecuencias de la aparición de defectos o vicios constructivos (así, la STS de 28 de enero de 1992 — aceptando la sentencia apelada—. Ponente: Magistrado Esteban Álamo -Ar. 1992/754-, define la recepción provisional como $<<\ldots$ una declaración de voluntad por virtud de la cual la obra es aceptada por la Administración, basándose para ello en el juicio positivo que arroja la verificación y que arrastra, como lógica consecuencia de la aprobación de la obra, su forma de posesión por la Administración con el fin de poder ser destinada al uso o servicio público previsto. Una vez recibida la obra provisionalmente el contratista solo responde de los vicios o defectos que puedan aparecer en el periodo de garantía. Por ello la recep-

\footnotetext{
${ }^{2}$ Como ejemplo de tal concepción baste citar a J.L. MARTín BLANCO; La compensación urbanística. Principios y sistema; Edit IEAL; Madrid, 1985; p. 214 y J.L. PIÑAR MaÑas; Sistema de Compensación y terceros adquirentes; Edit Montecorvo; Madrid, 1987; p. 56 y ss.
} 
ción definitiva tiene por objeto comprobar que durante el plazo de garantía la obra se ha mantenido en el debido estado de conservación>>, y en el mismo sentido se pronuncia la STS 18 de marzo de 1987. Ponente: Magistrado González Navarro; Ar. 1987\3779), cuando es lo cierto que, salvo que la legislación autonómica dispusiera otra cosa, tal posición sólo puede encontrar fundamento legal en la legislación de contratos de las Administraciones Públicas, pues la legislación urbanística estatal ha guardado tradicionalmente silencio al respecto. De hecho, si leemos con detenimiento el artículo 180.1 RGU, es evidente que el trámite de la recepción definitiva se vincula con la Junta de Compensación y no con el ayuntamiento, entidad, respecto de la cual, se predica únicamente la cesión o, desde su perspectiva, la recepción de las obras y servicios de urbanización ${ }^{3}$.

Pues bien, dicha relación contractual existe, por ejemplo, en el supuesto que contempla y analiza la STS de 26 de abril de 1985 (Ponente: Magistrado Rodríguez García; ar. 1985\2238), en el que el litigio se plantea en relación con la contratación por el Ayuntamiento de Teruel de las obras de urbanización de un determinado complejo educativo. De ahí que resulte correcta que la subsiguiente relación entre dicha Corporación local y el contratista de dicha obra se regule por la legislación de contratación administrativa vigente en aquel momento y por el régimen jurídico subsiguiente. Pero no es posible aplicar el mismo esquema a otros supuestos sustancialmente diferentes como son las actuaciones urbanísticas y en los que, como elemento cualificado, aparece la presencia de ciertos sujetos privados que desarrollan

\footnotetext{
${ }^{3}$ En cualquier caso, es preciso destacar que la todavía reciente reforma legislativa operada con la promulgación de la Ley 13/1995, de 18 de mayo, de Contratos de las Administraciones Públicas y la posterior entrada en vigor del Real Decreto Legislativo 2/2000, de 16 de junio, por el que se aprueba el Texto Refundido de la Ley de Contratos de las Administraciones Públicas, ha simplificado esta cuestión suprimiendo dicha dualidad de recepciones. En efecto, dicho texto legal (art 147 por remisión al art 110.2 del mismo texto), establece que, una vez terminadas las obras, dentro del mes siguiente, la Administración debe celebrar un acto formal al que ha de concurrir un facultativo designado por dicha administración, el facultativo encargado de la dirección de las obras y el contratista asistido, si lo estima oportuno, de su facultativo. Si las obras se consideran correctas con arreglo a las prescripciones previstas, el funcionario técnico designado y representante de la Administración contratante dan por recibidas las obras, circunstancia de la que se debe levantar acta, comenzando entonces el plazo de garantía. En caso contrario, se da un plazo para subsanar los defectos observados y, en caso de incumplimiento, se puede optar entre otorgar un nuevo plazo improrrogable o declarar resuelto el contrato. En el primer supuesto, comienza a correr el plazo de garantía que no puede ser inferior a un año y se debe establecer en el pliego de cláusulas administrativas particulares atendiendo a la naturaleza y complejidad de la obra. Trascurrido dicho plazo sin que se formulen objeciones por parte de la Administración se debe entender extinguida la responsabilidad del contratista.

En cualquier caso, es preciso destacar que tal posición en dada afecta al carácter de la relación Administración actuante-promotor (Junta de Compensación) sostenida en estas páginas y, por tanto, a la aplicación de tal texto legal.
} 
funciones netamente públicas de modo que entre la Administración actuante y estos sujetos se establece una relación (de tutela), cualitativamente diferente que va más allá de una relación propiamente contractual.

En efecto, como es sabido, la ejecución del planeamiento por el sistema de compensación se fundamenta en un régimen de auto-administración de los particulares en la gestión de una función o servicio público - la gestión urbanística- mediante la constitución por éstos de una entidad corporativa a la que el ordenamiento jurídico atribuye expresamente personalidad jurídica de naturaleza pública ${ }^{4}$, de modo que el ofrecimiento y posterior aceptación y recepción de las obras y servicios derivados de la urbanización no se fundamenta en una eventual relación contractual existente entre la Junta de Compensación y la Administración actuante. Se trata simplemente del cumplimiento de obligaciones inherentes a la dinámica del sistema de compensación. Dicha relación existe entre la Junta de Compensación, en tanto a ésta corresponde la contratación material de las obras de urbanización mediante las cuales se va produciendo la materialización del planeamiento y el o los contratistas de dichas obras; relación contractual que, en cuanto se trata de una obra pública [calificación expresamente atribuida por el art. 120.b) TRCA a los contratos que tengan por

\footnotetext{
${ }^{4}$ Tradicionalmente, la Junta de Compensación ha sido concebida como una entidad jurídica de naturaleza administrativa, con personalidad jurídica propia y plena capacidad para el cumplimiento de sus fines (la gestión de la urbanización y la justa distribución de beneficios y cargas entre los propietarios que la integran), sometida a la tutela de la Administración actuante; posición que encuentra confirmación reiterada en la jurisprudencia contencioso-administrativa. Sin ánimo de exahustividad valga como ejemplo la STS de 29 de diciembre de 1987 (Ponente: Magistrado Jiménez Hernández; ar. 198719854) a tenor de la cual, <<...las Juntas de Compensación no son similares a las sociedades civiles reguladas en los artículos 1655 y siguientes del Código Civil, pues aunque ellas tienen grandes concomitancias con tales sociedades, al referirse en algunos aspectos a derechos iusprivatísticos de sus componentes, ellas cumplen primordialmente funciones administrativas de orden urbanístico y es este carácter el que las define de forma más acusada, en cuanto tienen como fin último la realización de fines urbanísticos que, solo se pueden reputar cumplidos, cuando la Corporación Municipal a la que se hallan vinculados da por concluida la urbanización para cuya realización se constituyeron y recibe las obras ejecutada, no pudiendo, entre tanto, abandonar sus socios o componentes el ámbito de la misma, continuando hasta entonces sujetos a sus acuerdos y decisiones >>. Por lo demás, aquel tratamiento de la Junta de Compensación como persona jurídica de naturaleza pública no resulta en absoluto contradictorio. Se trata de una manifestación de un fenómeno conocido en el ámbito administrativo de atribución de una función pública (ejecución del planeamiento) en régimen de auto administración a los propios particulares interesados en la gestión, mediante la constitución de una entidad corporativa En efecto, en Derecho administrativo es frecuente que la Ley declare como público a un ente de base asociativa para atribuirle determinadas potestades públicas, bien en relación con un sector de actividad, bien sobre los miembros que lo integran. Se trata de los entes instrumentales de base corporativa cuyo fundamento radica en el interés que tiene la Administración en regular un determinado sector de actividad pero manteniendo la gestión en manos de los propios sujetos que la realizan. Ejemplo de esta consideración son los Colegios Profesionales o determinadas Organizaciones Profesionales.
} 
objeto actuaciones urbanísticas] se debe regir, esta vez sí, los la legislación contractual de las Administraciones públicas. Es preciso destacar que tal es la concepción que expresa la STS de 27 de junio de 1979 (Magistrado: Gabaldón López; Ar. 1979\2992) que establece la relación contractual —administrativa - propiamente entre la sociedad de compensación) y la sociedad adjudicataria de las obras. La primera es concebida como una auténtica administración pública, de ahí que se le reconozca la potestad de acordar o denegar el ejercicio de la cláusula de revisión de precios que pretendía ejercitar la segunda (de acuerdo con la entonces vigente Ley de Contratos del Estado de 8 de abril de 1965).

Ahora bien, el posterior ofrecimiento y consecuente recepción de las obras y servicios de la urbanización es un auténtico procedimiento administrativo de transferencia de bienes de una administración (Junta de Compensación) a otra (Administración actuante) que, por tanto, se rige por su normativa de carácter procedimental específica. Se explican, así, las normas reguladoras de esta cuestión previstas por la legislación autonómica ${ }^{5}$.

Excepción al respecto son aquellos modelos y sistemas de actuación en los que, a partir de la desvinculación entre la actividad urbanizadora y la propiedad del suelo - circunstancia que justamente define la concepción tradicional del sistema de compensación-, la elección del agente urbanizador se realiza mediante la celebración de un concurso dirigido a tal fin, estableciéndose de este modo una relación contractual entre dicho sujeto

\footnotetext{
${ }^{5} \mathrm{Si} \mathrm{bien,} \mathrm{la} \mathrm{regulación} \mathrm{autonómica} \mathrm{no} \mathrm{es} \mathrm{uniforme} \mathrm{al} \mathrm{respecto,} \mathrm{es} \mathrm{preciso} \mathrm{destacar} \mathrm{que} \mathrm{ha} \mathrm{venido}$ aceptando esta dualidad de recepciones; una primera de carácter provisional, a partir de la cual se abre un periodo de garantía, trascurrido el cual se produce, en caso de que no se pongan de manifiesto vicios o deficiencias constructivas, la recepción definitiva. Así, art. 142.3 LastS02 afirma que $<<$ Una vez recibidas las obras y aprobada, en su caso, la subsanación de los defectos observados, comenzará un plazo de garantía de un año de duración. Si al término de dicho plazo la Administración emite un informe favorable, o no se pronuncia durante los quince días siguientes a su conclusión, el contratista quedará relevado de toda responsabilidad sin perjuicio del régimen aplicable a los vicios ocultos $>>$. En parecidos términos el art $163.3 \mathrm{LrgS01}$ establece que $<<L a$ recepción de las obras cedidas tendrá carácter provisional durante un año a contar desde el día siguiente de la formalización del acta de cesión o de la fecha en que se hubiera producido la aprobación por silencio administrativo. Trascurrido el plazo del año sin notificación alguna del Ayuntamiento la recepción adquirirá carácter definitivo $>>$. Por su parte, el art $135.3 \mathrm{LmadS02}$ determina a partir de dicho momento el plazo de garantía que $<<\ldots$ no podrá ser inferior a un año $>>$. En este sentido, el art. 79.2 LvalS afirma que $<<$ Las obras de urbanización, realizadas por Urbanizador competente y ubicadas en dominio público, se entenderán aceptadas provisionalmente a los tres meses de su ofrecimiento formal al Ayuntamiento, sin respuesta administrativa expresa >>. Solamente, $<<\ldots$ A los nueve meses desde la aceptación provisional ésta devendrá definitiva, pasando los gestos de conservación a cargo de la Administración, salvo que ésta reclame la reparación de vicios $>>$. Sólo entonces el particular queda relevado de toda responsabilidad sin perjuicio, claro está, del régimen aplicable a los vicios ocultos. La misma conclusión se deduce del tenor del art 163.3 LrgS01.
} 
y la Administración actuante sobre la base un convenio suscrito entre ambas partes. En este sentido es claro el artículo 29.13 LvalS94 cuando afirma que $<<$ Las relaciones derivadas de la adjudicación del Programa se regirán por las normas rectoras de la contratación administrativa en lo que éstas no contradigan lo dispuesto por esta Ley ni sean incompatibles con los principios de la misma en los términos que reglamentariamente sean desarrollados $>>$. En el mismo sentido, el artículo $125 \mathrm{LcmS} 98$ establece que $<<$ Las relaciones derivadas de la Adjudicación de un Programa de Actuación Urbanizadora se regirán por lo dispuesto en esta Ley y, en el marco de la misma, en los Planes, el propio Programa y los actos adoptados para su cumplimiento, así como, supletoriamente, por las reglas del contrato de gestión de servicio público de la legislación reguladora de la contratación de las Administraciones Públicas $>>6$.

Por lo demás, puede ocurrir —en los sistemas de iniciativa pública— que sea la propia Administración actuante quien asuma no sólo la dirección del proceso de desarrollo urbanístico sino su ejecución material, contratando directamente con los contratistas correspondientes las obras necesarias con tal fin. En este caso, la recepción de las obras de urbanización se debe regir por la legislación de contratos de las Administraciones públicas.

Es preciso destacar finalmente que la posición sostenida en estas líneas ha sido adoptada, cabalmente, por alguna legislación autonómica. Así, la Ley 3/2002, de 19 de abril, de Régimen del Suelo y Ordenación Urbanística de Asturias —en adelante, LastS 02 - cuando afirma que $<<$ Si las obras de urbanización han sido encargadas por la Administración urbanística, su recepción se regirá por la legislación de contratos de las Administraciones Públicas. Si las obras han sido promovidas por otro sujeto, público o privado, su recepción por la Administración urbanística se adecuará a lo establecido en los restantes apartados de este artículo >> (art. 142.1 último inciso).

\section{ELEMENTO SUBJETIVO}

Dos son los sujetos implicados en el procedimiento de recepción de las obras y servicios de la urbanización. Por un lado, el promotor (la Junta de Compensación, el propietario único de los terrenos o, incluso, tratándose

\footnotetext{
${ }^{6}$ Otra cosa será que realmente se pueda sostener que dicha legislación autonómica prevalezca sobre la básica estatal restringiéndola a una mera aplicación supletoria o que las normas reguladoras de dicha contratación sean las del contrato de gestión de servicios públicos y no las propias del contrato de obra pública, de acuerdo con lo expuesto con anterioridad.
} 
de una actuación ejecutada por el sistema de expropiación, la Administración actuante cuando sea diferente al propio Ayuntamiento del término municipal donde se actúe), sujeto sobre el que recae el deber de instar de la Administración local la recepción de dichas obras y servicios mediante una petición formal realizada con tal fin, de modo que, una vez recibidas las obras de urbanización por parte del contratista, debe notificar al Ayuntamiento, en forma fehaciente, que ha sido ultimada la ejecución de aquéllas, interesando al propio tiempo la iniciación del correspondiente expediente de recepción municipal. Por otro, la Administración actuante.

En relación con el primer sujeto, es preciso indicar que siendo varios los promotores, sobre todos pesa tal deber, siendo de destacar que, como afirma las Ss. TS de 18 de octubre de 1998 (Ponente: Magistrado Jiménez Hernández; ar. 198817851) y 24 de abril de 1991 (Ponente: Magistrado Esteban Álamo; ar. 199113429), <<...las discrepancias internas entre los promotores no pueden trascender a sus relaciones con el Ayuntamiento en tanto ello no se haga patente e insoslayable...>>. Además, de acuerdo con la posición sostenida por algún pronunciamiento del TS (Sentencia de 13 de diciembre de 2000. Ponente: Magistrado Sanz Bayón; ar. 2000\10556), la cesión de las obras de urbanización ha de ser efectuada por la Junta de compensación y no, por la entidad de conservación que, en su caso, se halla constituido. Tal posición no resulta, sin embargo, afortunada. Con independencia de que es desconocida por el resto de la jurisprudencia analizada que admite con normalidad que el procedimiento de recepción se desarrolle entre dichas entidades y la Administración actuante, resulta contraria a la realidad de las cosas. En efecto, bastaría la mera transformación de la Junta de Compensación en una entidad de conservación, de acuerdo con el esquema legal, para que la recepción no se pudiera llevar a cabo.

En cualquier caso, se debe destacar que se trata de un deber que, incluso, puede ser forzado por el Ayuntamiento si este decide iniciar el procedimiento correspondiente, para lo cual, puede utilizar los medios de ejecución forzosa que estime necesarios, claro está, de acuerdo con los principios que rigen el ejercicio de tal potestad administrativa. En este sentido, la STS de 27 de junio de 1987 (Ponente: Magistrado Gordillo García; ar. 1983\3663) declara la nulidad de un acuerdo municipal que imponía una determinada sanción económica debido a la pasividad de los propietarios en orden a la formalización de la cesión de determinadas obras y servicios de urbanización, afirmando que $<<\ldots$ el Ayuntamiento pudo y debió interesar el cumplimiento de la formalización en la forma que reglamentariamente procediese pero nunca esgrimir su falta como motivo impe- 
diente de la recepción interesada, ni justificante de la sanción impuesta>>. Próximo es el caso que aborda la STS de 18 de junio de 1985 (Ponente: Magistrado Gutiérrez de Juana; ar. 198513224) que declara la nulidad de un acuerdo municipal que, debido a la inactividad de una cooperativa de viviendas y ante el requerimiento municipal para formalizar el acta de las cesiones obligatorias y la reparación de los desperfectos de la urbanización, impone una sanción de diez mil pesetas diarias por desobediencia a la autoridad municipal. En efecto, de acuerdo con lo dispuesto en aquel pronunciamiento judicial $<<\ldots$ carece de la cobertura legal que exige el artículo 107 de la Ley de Procedimiento, la medida coercitiva, adoptada en las referidas resoluciones; $y$ sin que tampoco pueda argüirse con fundamento, como se dice en aquellas alegaciones que la no aplicación de la medida compulsiva, acordada en las resoluciones impugnadas, suponga dejar libre de compromiso de la ejecución de las reparaciones, ordenadas al demandante, por cuanto cabe la ejecución subsidiaria a costa del mismo, como según parece desprenderse del expediente administrativo ya lo tiene previsto el Ayuntamiento $>>$. Finalmente, la STS de 28 de septiembre de 1987 (Ponente: Magistrado Brugera Manté; ar.1987\8264), reconoce la posibilidad de que el Ayuntamiento pueda acudir a la ejecución subsidiaria como medio para forzar la ejecución de las obras de urbanización pero matiza tal posibilidad en el sentido de que $<<\ldots$..la ejecución subsidiaria únicamente puede acordarse en defecto de cumplimiento voluntario por el obligado y resultando asimismo acreditado que en el presente caso la Administración Municipal inició la ejecución subsidiaria sin requerir ni conceder plazo a la Promotora para la realización voluntaria, es vista la procedencia de imponer al Ayuntamiento esta obligación...>>

Por lo demás, todas estas consideraciones no desvirtúan, a mi juicio, que cualquier otro sujeto que reúna la condición de interesado, de acuerdo con lo previsto en la LRJAP y PAC, pueda adoptar la iniciativa en orden a la iniciación del procedimiento, bien directamente ante la Junta de Compensación o entidad de conservación —en tanto órgano competente para ello-, bien ante el propio Ayuntamiento - en vía de recurso ante la posible denegación expresa o presunta de la Junta de Compensación en tanto administración de tutela, con lo cual, se lograría evitar dilaciones indebidas cuando estas son producidas por dichas entidades— ${ }^{7}$.

\footnotetext{
${ }^{7}$ La legislación autonómica aborda esta cuestión articulando un doble deber jurídico que simultáneamente recae, por un lado, sobre la Administración actuante, ordenado precisamente a recepcionar las obras de urbanización; y, por otro, sobre el sujeto responsable de la ejecución de la urbanización, dirigido a realizar la cesión correspondiente y cuyo cumplimiento puede ser forzado,
} 
ALGUNAS CUESTIONES EN TORNO A LA RECEPCIÓN DE LAS OBRAS Y SERVICIOS DE URBANIZACIÓN...

incluso, por la Administración actuante, si ésta acuerda iniciar de oficio el procedimiento correspondiente. En este sentido, la LmadS01 después de disponer que $<<$ La recepción de las obras de urbanización corresponde, al Ayuntamiento, de oficio o a instancia de la persona responsable de la ejecución, conservación y entrega de dichas obras $>>$ (art. 135.1), afirma que $<<$ La entrega de las obras de urbanización deberá realizarse por:

a) La persona o entidad, pública o privada, responsable de la ejecución según el sistema aplicado para la misma, incluida la Administración actuante, si es distinta de la municipal, cuando se trate de obras resultantes de una unidad de ejecución.

b) la persona, entidad o Administración que materialmente las haya ejecutado, en otro caso $>>$ [artículo 135.5 a) y b) de dicho texto legal].

En el mismo sentido se pronuncian los arts 152.1 LcanS00, 136.1 y 3 LcmS98, 162. 1 y 3 LextrS 01 .

Es preciso destacar, no obstante, que existen casos en los que parece que el procedimiento de recepción de las obras de urbanización no puede ser instado de oficio por la Administración actuante en tanto que la legislación aplicable sólo prevé que el inicio del procedimiento conducente a verificar tal recepciones se produzca a instancia de la persona o entidad promotora de la actuación, omitiendo toda referencia - como ocurre en los casos anteriores- a la iniciación de oficio por la Administración municipal. En este sentido, el art 45 a) RcatS 97 establece en los supuestos de ejecución de obras de urbanización por particulares o por entidades distintas del propio Ayuntamiento que $<<$ Concluida la obra se notificará tal hecho en forma fehaciente al Ayuntamiento, con solicitud de que se incoe el expediente de recepción de aquella>>. Por su parte, el art 163.1 LrgS01 establece que $<<$ Una vez terminadas las obras de urbanización e instalaciones y dotaciones, en su caso, el urbanizador o los propietarios lo pondrán en conocimiento del Ayuntamiento para su cesión >>. En parecidos términos se pronuncia el art 142.2 LastS02.

Por lo demás, la petición que debe ser comprensiva, junto a la pretensión propiamente dicha, de la documentación que acredite tanto la ejecución de las obras conforme al Proyecto, grado de ejecución material, su correcta ejecución o no y estado de conservación, si bien, la legislación autonómica es comprensiva también de otros documentos como el programa de control de calidad establecido para la obra previsto por la LmadS01 (art. 135.2) que se debe adjuntar al acta de recepción, haciendo constar su cumplimiento. El RcatS 97, se refiere a la copias de las actas de recepción de la obra realizada por el contratista de que se trate, descripción de los servicios a que se refiere, documentación gráfica donde se precise la obra realmente ejecutada con memoria justificativa de las posibles modificaciones que se hallan tenido que realizar respecto del proyecto aprobado y la valoración económica de los diferentes servicios a ceder al Ayuntamiento [art 45 c)]. Por su parte, el RbalS (art. 5.2), establece que a la notificación dirigida al Ayuntamiento, instándole a recepcionar las obras de urbanización se deben acompañar necesariamente, los siguientes documentos: a) copias autenticadas de las actas de recepción provisional y definitiva; b) Certificación expedida por la Empresa constructora, acreditativa que las obras se han ejecutado cumpliendo fielmente el Proyecto de Urbanización aprobado y que son aptas para ser ofrecidas al uso o servicio público; c) relación de los bienes y servicios de cesión obligatoria previstos en el Plan Parcial, Plan Especial, en su caso, y Proyecto de Urbanización; d) descripción de los bienes de los bienes y servicios, objeto de cesión, con especificación de su superficie, situación, características y titularidad dominical; e) certificación del Registro de la Propiedad acreditativa de la libertad de cargas y gravámenes de los terrenos objeto de cesión

Con el fin de evitar demoras, resulta interesante, la fijación de plazos y la consideración de la falta de colaboración con la administración municipal como una conducta ilícita que realiza el RbalS. Así, después de que el art 5.1 (segundo párrafo) de dicho texto reglamentario disponga que $<<E n$ el plazo máximo de tres meses contados desde la recepción definitiva de las obras de urbanización por parte del promotor o entidad promotora, se notificará de modo fehaciente al Ayunta- 
Ésta es justamente la solución arbitrada por algún pronunciamiento judicial (así, la ya citada STS de 4 de mayo de 1982 -Magistrado: Gordillo García; ar. 198213109-), de acuerdo con el cual, el promotor puede forzar la actitud municipal de mera pasividad ante el ofrecimiento de determinadas obras y servicios de urbanización provocando un determinado acto de la Administración actuante. En efecto, después de constatar la inactividad municipal en este sentido, afirma que $<<.$. frente a esa inactividad de la Administración, el interesado no se encuentra indefenso en modo alguno, porque puede y debe provocar un acto administrativo - expreso o por silencio-, acerca de que la Administración asuma su obligación de aceptar la cesión, para una vez obtenido el acto administrativo, acudir a la Jurisdicción Contenciosa solicitando que se declare la obligación de aceptar por parte de la Administración; que es lo que pudo hacer el interesado, conminando a la Administración a la aceptación, so riesgo de solicitar una declaración en tal sentido de los Tribunales; y al no haberlo hecho ha impedido que se produzca el acto administrativo que pueda ahora ser revisado, con la consecuencia de que, constando la falta de aceptación de la Administración (o mejor, su silencio o inactividad), necesariamente ha de concluirse afirmando las obligaciones en base a las cuales la Administración realizó el requerimiento que ahora se impugna>>.

La utilidad de esta vía es actualmente dudosa. En efecto, la sentencia citada tiene sentido bajo un esquema legal (Ley de Procedimiento Administrativo de 17 de julio de 1958) en el que la norma general del silencio administrativo era, previa denuncia de la mora, su carácter negativo circunstancia que provocaba la intervención revisora de la Jurisdicción contencioso-administrativa. Es justamente este esquema el que está presente en la sentencia citada. No obstante, tras la Reforma legislativa de 1992 la regla en nuestro caso es justamente la inversa, es decir, el silencio positivo. Recuérdese que el alcance de una y otra institución son diferentes; mera ficción legal de efectos exclusivamente procesales dirigida a la presunción del cumplimiento del acto consustancial a la configuración impugnatoria de la jurisdicción, en un caso y, resolución sustancial de una petición ante la inactividad administrativa, dando por producido el acto omitido por la Administración actuante, en el otro. Por tanto, realizado el ofrecimiento de unas obras de urbanización, el silencio municipal podría llevar a entender que la recepción efectivamente se ha producido. De esta

miento interesado que ha sido ultimada la ejecución de aquella y se interesará la iniciación del expediente de recepción municipal $>>$, el art.10.2 de la misma disposición afirma que $<<$ La negativa del promotor a colaborar con la Administración Municipal será considerado urbanísticamente como falta muy grave, sancionable en los términos previstos en el Reglamento de Disciplina Urbanística>>. 
forma, verificado el acto administrativo por silencio, aquella Administración no puede desconocerlo y, por tanto, no puede dictar actos nuevos que vengan a contradecirlo ${ }^{8}$. Ocurre, sin embargo, que en este ámbito del ordenamiento jurídico rige un principio, en virtud del cual, «en ningún caso se entenderán adquiridas por silencio administrativo facultades en contra de las prescripciones de esta Ley, de los Planes, Proyectos, Programas...» Que, de esta manera, supone un límite sustantivo al juego del silencio administrativo. Ciertamente el promotor puede entender que la recepción efectivamente se ha producido pero tal interpretación y su materialización se hace a su entero riesgo y a él son imputables sus consecuencias pues la Administración puede seguir actuando como si tal recepción no se hubiera verificado. De esta forma, la resolución del conflicto en sede judicial es inevitable.

Es preciso destacar que la obligación que recae sobre la Administración local de recibir las obras y servicios de urbanización, cuando tienen la exi-

\footnotetext{
${ }^{8}$ Es preciso destacar que ésta es justamente la solución adoptada por la legislación autonómica que por regla general establece un plazo máximo, contado a partir de la comunicación al ayuntamiento de la finalización de las obras de urbanización e interesando del mismo su recepción, para que dicha entidad resuelva trámite lo que estime oportuno en relación con dicha comunicación y, trascurrido el cual, entender materializada la cesión. Así, el art 46 RcatS 97 dispone que $<<$ Si el órgano actuante no resuelve expresamente sobre la recepción de las obras en el plazo de tres meses, se entenderá estimada la petición y el solicitante podrá actuar de acuerdo con lo que se dispone en la normativa sobre actos administrativos presuntos $>>$. Por su parte, la LmadS01 establece que $<<$ En el caso de que la Administración no resolviera sobre la recepción de las obras de urbanización en el plazo previsto en el planeamiento u ordenanza municipal o, en su defecto, en el de tres meses, bastará el ofrecimiento formal de cesión de las mismas por la persona responsable de la ejecución, a los efectos de entender recepcionadas las obras >> (art 135.8). Previsiones en idéntico sentido establece el art 136.4 LcmS98, el art. 162.4 LextrS 01, el art. 163.2 LrgS01 o el art. 79.2 LvalS 94. En el caso de la LastS (art 142.2) dicho plazo se reduce a dos meses. Es preciso destacar que tal efecto se produce, incluso, aunque las obras o servicios objeto de recepción contengan vicios y defectos, si éstos, no son puesto de relieve en el plazo legalmente previsto para proceder a su recepción. Así, la LastS (art 142.2) después de afirmar el deber de la Administración actuante de proceder a la recepción de las obras correspondientes y establecer un plazo para ello — dos meses-, establece que $<<\ldots$. Si, en el citado plazo, la Administración urbanística no hubiera comunicado por escrito al promotor las deficiencias o defectos observados en las obras de urbanización, instalaciones o dotaciones, se entenderá aprobada la recepción por silencio administrativo $>>$. Y es preciso destacar que el mismo efecto se puede producir en un momento posterior, una vez ejecutadas las obras necesarias para remediar los defectos observados, si dicha Administración no se pronuncia expresamente al respecto: $<<L a$ Administración urbanística deberá pronunciarse expresamente sobre las obras ejecutadas para subsanar las deficiencias observadas. Si no se pronuncia en el plazo de un mes a contar desde la comunicación escrita de la conclusión de las citadas obras, se entenderá que han sido aprobadas >>.
}

Por lo demás, en el caso de Castilla- La Mancha (art 136.4) y de Extremadura (art. 162.4) el plazo inicialmente previsto para entender producida por silencio la recepción (tres meses), puede ser prorrogado por la mitad del tiempo por razones justificadas en las necesarias comprobaciones del estado de las obras, construcciones o instalaciones. 
gible aptitud y calidad para ser entregadas, es entendida por el TS como un deber en sentido estricto. Así, desde esta perspectiva, La STS de 22 de diciembre de 1987 (Ponente: Magistrado González Navarro; ar 1987\9669 afirma que $<<\ldots$ el Ayuntamiento tiene el deber de dar curso procesal a la solicitud formulada de aceptación de los terrenos y recepción de los servicios, debiendo, en consecuencia, abrir el oportuno expediente. Pues de no hacerlo está obstruyendo el ejercicio de un derecho que la Ley otorga a la empresa urbanizadora, $y$, en la medida en que se produzca demora en la tramitación de ese expediente o cualquier forma de desvío de las previsiones contenidas en el ordenamiento jurídico, se estaría dando un anormal funcionamiento de la actividad administrativa que podría, en consecuencia, dar lugar a exigencia de responsabilidad $>>$. Y, desde esta misma perspectiva, la STS de 28 de enero de 1992. (Ponente: Magistrado Esteban Álamo - Ar. 1992/754-) califica expresamente la obligación comentada como $<<\ldots$ deber urbanístico... $>>$.

\section{ELEMENTO OBJETIVO}

El objeto de la recepción son las obras y servicios previstos por el planeamiento y por el proyecto de urbanización, tales como viales, parques y jardines públicos, zonas deportivas, de recreo y expansión, centros culturales y docentes, es decir, en general, las dotaciones propias de la actuación. No constituyen objeto de este procedimiento las cesiones obligatorias y gratuitas cuya cesión, de acuerdo con la dinámica del proceso de ejecución del planeamiento, se debe haber realizado con anterioridad. En caso contrario, se debe realizar en expediente separado. La jurisprudencia contencioso-administrativa (así, la STS de 11 de octubre de 1982. Ponente: Magistrado Díaz Eimil; ar. 1982\6355), se ha encargado de sustantivizar y diferenciar ambas obligaciones y, así, frente a la pretensión del promotor de dar por cumplido el deber de ejecutar y ceder las obras y servicios de urbanización, mediante la simple cesión de los terrenos que constituyen el soporte físico de aquéllas, destaca que $<<$...la cesión de terrenos y el costeamiento de las obras de urbanización son obligaciones distintas, sometidas a un régimen de cumplimiento independiente, pues mientras que la primera se satisface a través de la correspondiente acta de entrega y recepción, que produce la trasmisión al Ayuntamiento de la titularidad dominical de los terrenos cedidos, la segunda no recae sobre éstos, sino sobre las obras de urbanización, cuyo traslado al Ayuntamiento requiere que los propietarios ofrezcan la cesión de las obras urbanizadas en debidas condiciones y la autoridad municipal, previa comprobación de las mismas las acepte mediante un acto expreso de recepción 
definitiva... >>. Más claramente, en la medida en que objeto del pronunciamiento jurisprudencial no gira tanto en relación con el alcance de la obligación, cuanto, más bien, respecto de los bienes afectados por dicha obligación, la STS de 27 de junio de 1983 (Ponente: Magistrado Gordillo García; ar. 198313663), afirma que $<<\ldots$ una cosa es la cesión gratuita de dichos terrenos, destinados a viales y zonas ajardinadas entre bloques, y otra muy distinta, la cesión de las obras de urbanización ejecutadas sobre dichos terrenos, es decir, de los viales ya construidos o de las zonas ajardinadas verificadas y a las plantaciones previstas, cuya cesión, obviamente no puede realizarse hasta que dichas obras no estén materialmente realizadas por la empresa promotora de la urbanización; siendo estas obras de urbanización - como elemento diferenciado de los terrenos en que las mismas se llevan a cabo-, las que evidentemente se está exigiendo por el Ayuntamiento que se formalice su cesión;... >>. Se trata de una posición unánimemente aceptada por la jurisprudencia contencioso-administrativa y, así, se pronuncian las Ss.TS de 28 de noviembre de 1984 (Ponente: Magistrado Delgado-Iribarren Negrao; ar. 1984l6623), de 7 de noviembre de 1988 (Ponente: Barrio Iglesias; ar. 198818786), de 4 de marzo de 1989 (Ponente: Magistrado García Estartús; ar. 1989\1723)

Conviene reiterar que la obligación comprende sólo y estrictamente aquellas obras y servicios. Aparece, pues, un primer requisito relativo a la exigibilidad de tales dotaciones. En efecto, el Ayuntamiento no puede imponer unilateralmente a los promotores mayores exigencias u obligaciones diferentes a las previstas por aquellos instrumentos urbanísticos a través de cláusulas que, de acuerdo con la teoría general del acto administrativo, consideraríamos como accesorias o impropias ${ }^{9}$. En este sentido, el TS en la anteriormente citada S. de 28 de enero de 1992 frente a la pretensión de la Gerencia de Urbanismo de Madrid de condicionar la recepción de la urbanización a la entrega de cierta documentación (tres colecciones de planos de liquidación de todos los servicios urbanos instalados, que definan suficientemente las obras realizadas; conformidad expresa a las redes instaladas de las Compañías de Servicios; Compromiso notarial de conservación de las zonas ajardinadas) y a la obligatoriedad de unas cesiones, en ambos casos no previstas, ni por ley, ni por los instrumentos de planeamiento vigentes, afirma que $<<$ Las exigencias del Decreto aquí impugnado son inoperantes, ya que no responden a condiciones fijadas en el plan o en el Proyecto de Urbanización ni figuran en la documentación

\footnotetext{
${ }^{9}$ En este sentido, el ap. 1 del art 142 LastS02, después de afirmar la obligación de la Administración actuante de recepcionar la obras de urbanización, establece que $<<\ldots$ la cual habrá de realizarla atendiendo únicamente al cumplimiento de las previsiones y especificaciones contenidas en el Proyecto de Urbanización definitivamente aprobado >>.
} 
de los mismos que hubiera condicionado, en su caso, la recepción provisional, ya que en cuanto al compromiso notarial de conservación, no tiene fundamento legal y está en clara contradicción con los propios términos establecidos por la Gerencia Municipal de Urbanismo en el acta de cesión gratuita de terrenos, pues el compromiso de mantener y conservar las zonas verdes se extiende «hasta tanto se efectúe por la Corporación la recepción definitiva de las obras de urbanización» momento en que se produce la liberación efectiva de la carga de conservación. Igual suerte la exigencia de aportar tres colecciones de planos de los servicios urbanos instalados que definan suficientemente las obras realizadas y conformidad expresa a las redes instaladas de las Compañías de servicios, por no existir tampoco norma alguna en la legislación aplicable a la ejecución del Plan Parcial que fundamente tal solicitud, amén de ser un requisito nuevo, no indicado en anteriores actos (as. XIV-77 y 76) y cuyo cumplimiento determinaría, según la Administración la formalización del acta de recepción definitiva $>>$. Y finalmente afirma que $<<$ La obligación de completar las cesiones obligatorias y gratuitas de terrenos afectados por el $4 .^{\circ}$ cinturón, igualmente exigido en el auto recurrido, debe ser igualmente rechazada, al no estar acreditado por la Administración que tales terrenos formen parte de los que deben ser cedidos obligatoria y gratuitamente según el planeamiento urbanístico vigente. Así resulta de la Memoria, de los plazos de la documentación urbanística oficial y de los propios actos administrativos de ejecución del Plan Urbanístico. Se trata de terrenos de reserva o cesión obligatoria para el cuarto cinturón pero ello no implica que tengan que incluirse entre las cesiones gratuitas del Ayuntamiento que fueron todas objeto del acta administrativas preparada por la Gerencia Municipal de Urbanismo y firmada por la Entidad actora, por lo que procede, estimar en su totalidad la demanda>>.

Incluso en casos extremos como el que analiza la STS de 18 de septiembre de 1990 (Ponente: Magistrado Esteban Álamo; ar. 199017096) en el que el sistema de evacuación de aguas podía causar un serio riesgo de salubridad pública en la urbanización, siendo necesaria la ejecución de una red de alcantarillado que sustituyese a los pozos absorbentes o, el simple desagüe a barrancos, inicialmente previstos, el TS afirma que si bien, el Ayuntamiento está perfectamente legitimado e incluso obligado para adoptar las medidas necesarias para salvaguardar la salubridad de las aguas y, en definitiva la salud de los ciudadanos salud pública, no es menos cierto que ello no puede implicar para el promotor mayores obligaciones que las previstas en el plan. El argumento del Tribunal es concluyente: $<<$ El Ayuntamiento recibió la urbanización, manifestando su conformidad en el sentido de que tal urbanización había sido ejecutada de 
acuerdo con lo establecido en el Plan Parcial aprobado, plan posteriormente incorporado al General del Municipio, y por tanto en principio los propietarios de las parcelas de la urbanización no tienen más obligaciones que las de cualquier otro propietario de una parcela urbana >>. En el mismo sentido se pronunciaba ya la STS de 24 de febrero de 1987 (ar. 1987/3361) en un caso prácticamente idéntico. Por su parte, la STS de 20 de junio de 1988 (Ponente: Magistrado Brugera Manté.; ar.1988\4400) declara la nulidad de sendos acuerdos municipales que pretendían supeditar la aceptación y recepción de determinado servicio (vía principal de acceso a una urbanización) a la realización de nuevas obras que nada tenían que ver con los requisitos a cuyo cumplimiento el Ayuntamiento había condicionado inicialmente dicha recepción.

Por el contrario, la jurisprudencia (STS de 17 de diciembre de 1985. Ponente: Magistrado: Díaz Eimil; ar. 1985\6398) admite la validez de ciertas exigencias - acreditación de la total terminación de las obras de urbanización, superficie y localización de los viales, espacios libres y equipamientos colectivos, titularidad del alcantarillado, convenios y compromisos adquiridos con las empresas suministradoras de servicios etc...-, cuando están ordenadas a garantizar la ejecución del planeamiento correspondiente $<<\ldots$ tales acuerdos no suponen otra cosa que medidas destinadas a garantizar el cumplimiento de las previsiones del Plan Parcial en ejecución del cual se realizan dichas obras de urbanización, siendo incuestionable que su legalidad, sin necesidad de acudir a preceptos más específicos, viene plenamente amparada en la fuerza obligatoria de los instrumentos de planeamiento, establecida en el artículo 57 de la Ley del Suelo y en la condición ejecutiva que los proyectos de urbanización ostentan respecto de los planes según dispone el artículo 15 de la misma Ley.>>. Es decir, actúan como compitio iris.

\section{VERIFICACIÓN DE LAS OBRAS Y SERVICIOS POR PARTE DE LA ADMINISTRACIÓN ACTUANTE; SUBSANACIÓN DE VICIOS O DEFECTOS ${ }^{10}$}

La verificación de las obras y servicios consiste en una comprobación que trata de determinar la conformidad de éstas con el Plan o proyecto de

\footnotetext{
${ }^{10}$ Es preciso destacar que las Comunidades Autónomas que regulan esta cuestión no establecen un procedimiento completo y acabado de esta cuestión. Se trata de una regulación fragmentaria, centrada en determinadas cuestiones pero que no da respuesta, ni de lejos Por tanto, debe ser integrada por el operador jurídico de acuerdo con el marco normativo expuesto con anterioridad. Canarias y Castilla-La Mancha no establecen previsión de carácter procedimental destinada a integrar
} 
urbanización aprobado, su correcta ejecución y su estado de conservación. La ya citada STS de 28 de enero de 1992 define en este sentido el trámite de verificación de aquéllas como $<<\ldots$ un examen para determinar si se ha ejecutado de acuerdo con lo establecido... >> y cuyo resultado es la aprobación de la obra, es decir, $<<\ldots$ el juicio emitido de la verificación y que implica la obligación de aceptarla >>. Es al ayuntamiento a quien corresponde realizar tales tareas.

En cualquier caso, es preciso destacar la importancia de este trámite. En efecto, el deber de recepción de las obras y servicios de urbanización que, como ya nos consta, recae sobre el Ayuntamiento, no implica necesariamente un deber incondicionado ordenado a la recepción inmediata de dichas obras y servicios por parte de la Administración municipal una vez concluidas y producido el correspondiente ofrecimiento en tal sentido, sin atender a otra circunstancia, como única hipótesis posible. Y ello, porque la inexistencia de vicios o defectos - jurídicos y materiales - en las obras y servicios de urbanización es requisito necesario para que la recepción de éstas se pueda verificar. Si no se encuentran en las debidas condiciones, aquella Administración no está obligada a ello. De esta manera, una vez recibida la solicitud de recepción de las obras y de los servicios correspondientes o, en su caso, acordado de oficio el inicio del procedimiento conducente a tal fin, el ayuntamiento de que se trate debe comprobar, a través de los medios de prueba que estime convenientes, que aquéllos han sido ejecutados de acuerdo con las condiciones anteriores y que, por tanto, son conformes para su destino público. De ahí, que si en el procedimiento de recepción se detecta la existencia de aquellas deficiencias, deben ser subsanadas.

Es preciso destacar que la jurisprudencia contencioso-administrativa exige desde esta perspectiva un acuerdo de voluntades entre las dos partes implicadas, acuerdo que excluye iniciativas más o menos informales y que debe versar sobre dos circunstancias que, en su caso, pueden legitimar la negativa municipal. Por un lado, la ejecución total de las obras de urbanización; por otro, su conformidad con el plan o proyecto de urbanización y con su buen estado de conservación. A dicha concurrencia de voluntades se refiere la STS de 4 de mayo de 1982 (Ponente: Magistrado Gordillo García; ar. 1982/3109) que destaca que $<<$...la cesión no depende exclu-

el procedimiento de recepción de las obras de urbanización, remitiéndose al respecto a lo que en su momento se establezca vía reglamentaria. Sólo Baleares regula un procedimiento con dicha vocación de plenitud pero circunstancias, tanto el tiempo transcurrido desde el dictado de la disposición como la complejidad de la cuestión, determinan igualmente la insuficiencia de la norma para dar respuesta adecuada a todos los problemas planteados. 
ALGUNAS CUESTIONES EN TORNO A LA RECEPCIÓN DE LAS OBRAS Y SERVICIOS DE URBANIZACIÓN..

sivamente de que el promotor o la Junta de Compensación correspondiente otorgue escritura pública diciendo que cede viales, zonas verdes y servicios, sino que la Administración, tras la observancia de si los mismos se encuentran con las dotaciones pertinentes, acepte el ofrecimiento que se le hace, pues, de entenderlo de otro modo, es decir, concluyendo que el puro ofrecimiento consuma la cesión, llegaría a la grave consecuencia de que, en cualquier momento y con las deficiencias que se quisiera, el cedente podría desligarse de sus obligaciones urbanizadoras...>>, de donde concluye el tribunal afirmando que, como en el caso de autos, se ha probado que existe el ofrecimiento pero no la recepción, el promotor viene obligado no sólo al establecimiento de los servicios (alumbrado público, red de riego y enlace de éstos con las redes generales) sino, a su mantenimiento. Más adelante volveremos sobre esta cuestión. Se trata ahora de analizar los dos presupuestos determinantes de la recepción citados con anterioridad.

\section{a) Ejecución total de la urbanización}

Como hemos apuntado, la jurisprudencia condiciona la posibilidad de que la Administración actuante recepcione las obras y servicios de la urbanización, por un lado, al cumplimiento de un primer requisito como es coherentemente la total terminación de las obras de urbanización. Lógicamente, si éstas no han sido terminadas, salvo que sea posible materializar una recepción parcial, el procedimiento de recepción carece de elemento material ${ }^{11}$. Así se expresa la STS de 14 de abril de 1983 (Ponente: Martín del Burgo y Marchán; ar. 1983 2088) cuando afirma que <<...la cesión y

\footnotetext{
${ }^{11}$ Conviene destacar en este lugar que siguiendo la posibilidad ya abierta por el art. 180.2 RGU, la normativa autonómica acepta la posibilidad de que se produzcan recepciones parciales, si bien, no es unánime la exigencia de su unidad funcional y, así, mientras el RbalS87 afirma que $<<\ldots$ podrá solicitarse la recepción municipal de una parte del polígono o unidad de actuación aún cuando no se halla completado la obras de urbanización de este ámbito territorial,, siempre que el área urbanizada constituya una unidad funcional directamente utilizable y se haya producido respecto a la misma la recepción definitiva por parte del promotor o entidad promotora >>, no parece que sea el caso de la LastS02, que admite $<<\ldots$ recepciones parciales de obras de urbanización, instalaciones o dotaciones siempre que las mismas pudieran ser susceptibles de destinarse al uso previsto con independencia de las demás >> (art 142.1). En el mismo sentido, el texto catalán [(art. 45 b)] contempla la posibilidad de que el objeto de la recepción sean determinados servicios siempre y cuando se trate expresamente de servicios completos, destacando al respecto que $<<$ Lo dispuesto en el párrafo anterior será aplicable a la urbanización realizada sobre fases determinadas previstas en el proyecto de urbanización o a servicios completos, aunque no se hubieran ejecutado las obras correspondientes a la totalidad de la obra prevista >>. Por lo demás, es preciso destacar que las obras de urbanización pueden ser objeto de recepción parcial cuando sean susceptibles de ser ejecutadas por fases independientes capaces de prestar el uso o servicio públicos correspondientes (arts 135.7 LmadS y 152.3 LcanS00).
} 
la correlativa asunción de obligaciones, por parte del Ayuntamiento de Paterna, no puede ser impuesta a éste, al faltar un requisito esencial: la terminación de la gestión urbanística en los terrenos comprendidos dentro del polígono o unidad de actuación delimitados de acuerdo con el Plan Parcial ordenador de los mismos $>>{ }^{12}$. En el mismo sentido se pronuncian, en otras, las Ss. TS de 9 de mayo de 1985 (Ponente: Magistrado Díaz Eimil; ar. 1985\2903), o 29 de diciembre de 1987 (Ponente: Magistrado Jiménez Hernández; ar. 1987\9854), de 16 de septiembre de 1988 (Ponente: Magistrado Esteban Álamo; ar. 1988\6711).

\section{b) Conformidad con el Plan o Proyecto de urbanización, corrección de su ejecución y su buen estado de conservación}

Por otro lado, la recepción se debe producir, únicamente, si las obras y servicios que se pretenden entregar son conformes con el Plan o con el Proyecto de urbanización, es correcta su ejecución y, además, se encuentran en buen estado de conservación. En este sentido, la STS de 7 de diciembre de 1981 (Ponente: Magistrado Díaz Eimil; ar. 198115368) afirma que los graves defectos e insuficiencias de todo tipo de que adolece determinada urbanización $<<\ldots$ legitiman a la Corporación Municipal para negarse a la recepción de la urbanización mientras no se subsanen esos defectos e insuficiencias así como a adoptar todas aquellas medidas que la ley le concede en orden a imponer a dicho promotor su reparación, entre las cuales es indudable que vienen incluidas la de exigirle un proyecto de obras que a tal fin deban ser realizadas y ejercitar su potestad sacionadora en caso de falta

\footnotetext{
${ }^{12}$ Se trata de un deber al que, de acuerdo con la jurisprudencia contencioso-administrativa (STS de 5 de febrero de 1985. Ponente: Magistrado Delgado-Iribarren Negrao; Ar 19851990), deben contribuir económicamente todos los propietarios, incluidos el Ayuntamiento (por el 10 por 100 de la cesión de aprovechamiento) que fundamentando tal posición afirma que $<<\ldots$ el art. $163 \mathrm{del}$ citado Reglamento de Gestión que establece que «las Entidades públicas titulares de bienes incluidos en el polígono o unidad de actuación, ya tengan carácter demanial o patrimonial» se integrarán en la Junta de compensación con plenitud de derechos, lo que de suyo implica tanto participación en las decisiones y provechos como en las cargas, debiendo destacarse que si esta condición la determina la sola titularidad de bienes «demaniales», con mayor razón deberá atribuirla el diez por ciento del aprovechamiento medio, que se materializa en terrenos destinados a ser comercializados en el mercado libre, y $4^{\circ}{ }^{\circ}$ ) la corrobora asimismo el art. 168 del mismo Reglamento que afirma que "todos» los terrenos comprendidos en el polígono o unidad de actuación «quedarán directamente afectados al cumplimiento de las obligaciones inherentes al sistema», lo que significa que estas obligaciones constituyen cargas reales, «ob rem», que se imponen a quien quiera que sea el titular de los terrenos, sin que pueda admitirse ninguna exención que no esté expresamente determinada en un precepto legal >>. En el mismo sentido, la STS de 20 de marzo de 1989 (Ponente: Magistrado Esteban Álamo; ar. 198912244) que reitera tal obligación, aun en el caso de incumplimiento de los promotores en cuanto a la terminación de las obras y de falta de recepción formal de las obras por parte municipal.
} 
ALGUNAS CUESTIONES EN TORNO A LA RECEPCIÓN DE LAS OBRAS Y SERVICIOS DE URBANIZACIÓN..

de presentación del mismo e incluso redactarlo de oficio y proceder a su ejecución a costa del citado promotor, que es el único que debe soportar las consecuencias perjudiciales de la manifiesta ilegalidad con que ha llevado a cabo la mencionada urbanización, sin perjuicio de las acciones de reintegro que en el orden civil puedan corresponderle... >>. En el mismo sentido, se expresan las Ss. TS de 17 de noviembre de 1981 (Ponente: Magistrado Esteban Álamo), ar. 198115146-; 28 de junio de 1982 (ar. 1982\4859), 8 de marzo y 28 de junio de 1983 (ar. 1983\1388 y 1983\3669), 2 de abril de 1984 (ar. 1984\2553), 18 de marzo y 26 de septiembre de 1987 (Ponentes: Magistrados González Navarro y Brugera Manté; ar. 1987\3779 y 1987\8264, respectivamente) y de 4 de marzo de 1989 (Ponente: Magistrado García Estatus; ar, 1989\1723).

De esta forma, si bien, la misma jurisprudencia contenciosa (Sentencia de 11 de octubre de 1982. Ponente: Magistrado Díaz Eimil; ar. 198216355) define la recepción como $<<\ldots$ un acto reglado que la Administración no puede evitar... >>, acto seguido matiza tal afirmación destacando que tal circunstancia sólo se produce $<<\ldots$ si se le ofrecen las obras en las condiciones debidas...>>. El mismo pronunciamiento contienen, entre otras, las Ss. de 7 de noviembre de1988 (Ponente: Magistrado Barrio Iglesias; ar. 198818786) y de 4 de marzo de 1989, citada anteriormente.

En cualquier caso, es preciso destacar que la propia jurisprudencia contencioso-administrativa modula la responsabilidad del promotor desde dos perspectivas. Por un lado, los defectos o vicios en los que se pretende fundamentar la negativa municipal a materializar la recepción deben tener una importancia y entidad suficiente para ello. No es suficiente, por tanto, cualquier irregularidad. Por otro, no deben ser consecuencia del uso público de la urbanización. Así, en un caso en el que la Gerencia de Urbanismo de Madrid se negaba a recepcionar definitivamente unas obras de urbanización señalando, junto a otros motivos que indicaremos más adelante, la existencia de ciertos defectos en las mismas tales como rejillas rotas, una cala en la acera sin tapar, varios puntos de luz y bocas de riego sin funcionar, el TS (S. de 28 de enero de 1992 - aceptando la sentencia apelada-. Ponente: Magistrado Esteban Álamo; ar. 1992/754) tras calificar dichas deficiencias como <<...mínimos, y propios de los nueve años de uso público de la urbanización $>>$, y destaca que $<<\ldots$ el actor sólo es responsable de los gastos y de los daños y deterioros que se ocasionen durante el plazo de garantía, pero no de los que se originen fuera de él, y tal responsabilidad sólo puede ser exigida bajo el supuesto de cumplimiento del plazo legal del trámite de recepción definitiva de las obras, en la que tales daños o deterioros deben ser constatados $>>$. En el mismo sentido, se 
pronuncian las Ss. TS de 27 de junio de 1983 (Ponente: Magistrado Gordillo García; ar. 1983\3663) en relación con el servicio de alumbrado y ciertos trabajos de jardinería, de 30 de marzo de 1984 (Ponente: Magistrado Marín Ruiz; Ar. 1984|2624) respecto de ciertos defectos de conservación en la calzada y aceras, falta de tapas de imbornales y existencia de ciertos cables al descubierto y de 4 de junio de 2002 (Ponente: Magistrado Garzón Herrero; ar. 200215799), en relación con ciertos defectos existentes en la línea telefónica.

En otras ocasiones la jurisprudencia desestima la pretensión municipal de negar la aceptación de la urbanización cuando el mal estado de las obras - circunstancia de hecho en que se fundamenta dicho acuerdo- es consecuencia de la negligencia municipal a la hora de verificar su estado. Y así, la STS de 26 de abril de 1985 (Ponente: Magistrado Gordillo García; ar. 1985\3527) entre los motivos alegados para desestimar la pretensión municipal destaca, justamente, el carácter visible de los servicios que el Ayuntamiento considera en mal estado (alumbrado público, abastecimiento de agua potable y alcantarillado), apreciación que, además, lleva al Tribunal a negar el carácter de vicio oculto a las deficiencias alegadas afirmando que $<<\ldots$ por versar sobre servicios tan ostensibles como primordiales y debieron ser apreciadas, en su caso, por el Ayuntamiento antes de proceder a la recepción sin reparo alguno de las obras ya entonces ejecutadas, habiendo transcurrido más de cinco años hasta que la Corporación municipal aprecia deficiencias en el funcionamiento de esos básicos servicios $>>$.

Aunque la jurisprudencia no se pronuncia de forma expresa y directa al respecto, parece evidente que el resultado de tales comprobaciones debe ser recogido en un informe emitido por los servicios municipales Tal afirmación no significa necesariamente que tal acción de comprobación tenga que ser realizada directa y materialmente, de forma necesaria, por los servicios municipales. Tal posición es contraria a la propia realidad de las cosas e implica, necesariamente, que en multitud de ocasiones, dicha actuación se realice sin las debidas garantías o, simplemente, no se pueda materializar. Pensemos en los numerosos Ayuntamientos que carecen de los recursos humanos y de medios técnicos necesarios para realizar una actividad tan técnica y especializada como la que nos ocupa. De esta forma, si bien es cierto que la Administración local no puede acudir a fórmulas de gestión indirecta para realizar estas tareas dado el ejercicio de autoridad que implican y que es inherente a las mismas, sí es posible, sin embargo — de acuerdo tanto con la legislación básica estatal en materia de régimen local, como con la legislación urbanística, ya sea de carác- 
ter autonómico, ya sea estatal supletoria—, su desarrollo en régimen de descentralización funcional, mediante la personificación de un ente de carácter instrumental, diferenciado de la propia organización municipal $\mathrm{y}$ al que se encomienda el desarrollo de aquellas funciones (Gerencia). Pero también puede lícitamente acudir a cualquiera de las fórmulas voluntaria de cooperación interadministrativa previstas por el ordenamiento ${ }^{13}$. En cualquier caso, se debe indicar que los informes de los servicios técnicos municipales tienen una importancia fundamental hasta el punto de que el Ayuntamiento no puede ir en contra de lo establecido por sus propios servicios municipales. De este modo, si dichos servicios, bien no detectan deficiencias o vicios en las obras, bien no alcanzan a impedir - a su parecer - la recepción, la posible negativa municipal no se puede fundamentar en estos extremos y puede resultar ilícita. Así, las Ss. TS de 13 de marzo de 1987 (Ponente: Magistrado Brugera Manté; ar. 1987\3645)y de 20 de junio de 1988. Ponente: Magistrado Brugera Manté; ar. 1988\4400).

En cualquier caso, la Administración actuante debe detallar documentalmente y con precisión suficiente cuales son los defectos o irregularidades que impiden llevar a término la recepción y los plazos previstos para la subsanación. La jurisprudencia es unánime al respecto y, así, junto a las ya citadas Ss. TS 27 de junio de 1983 (Ponente: Magistrado Gordillo García; ar. 198313663) y de 30 de marzo de 1984 (Ponente: Magistrado Marín Ruiz; ar. 1984|2624), podemos citar las Ss. TS de 22 de julio (Ponente: Magistrado Gordillo García; Ar. 198615545) y 19 de diciembre de 1986 (Ponente: Magistrado Gutiérrez de Juana; ar. 1986\1171), STS de 13 de marzo de 1987 (Ponente: Magistrado González Navarro; ar. 1987\3779) ${ }^{14}$.

\footnotetext{
${ }^{13}$ A mero título de ejemplo baste recordar que la LmS 01 (art. 74.2) legitima a las administraciones competentes a adoptar alguno de los siguientes acuerdos:

a) Constituir consorcios, transfiriendo a estos sus competencias.

b) Crear Mancomunidades de municipios para la gestión de servicios urbanísticos.

c) Delegar competencias propias en otras Administraciones, organismos de ellas dependientes o entidades públicas por ellas fundadas o controladas.

d) Utilizar órganos de otras Administraciones o de los organismos dependientes o adscritos a ellas, para la realización de tareas precisas para el ejercicio de competencias propias.

${ }^{14}$ En este sentido, la LmS01 dispone que si en el momento de la recepción las obras, éstas se encuentran en buen estado y han sido ejecutadas con arreglo a las prescripciones previstas, el funcionario técnico designado por el Alcalde las debe dar por recibidas, haciéndolo constar en acta levantada al efecto (ap. 3). En la hipótesis contraria, es decir, cuando las obras no se hallen en estado de ser recibidas, se debe hacer constar así en el acta, señalando los defectos observados y detallando las instrucciones precisas para remediarlos, para lo cual, se debe establecer un plazo determinado para la subsanación (ap. 4). Por su parte, el art 45 d) del RcatS 97 dispone desde la
} 
Por lo demás, la carga de la prueba de que las obras de urbanización han sido ofrecidas en las debidas condiciones corresponde de acuerdo con la STS de 11 de octubre de 1982 (Ponente: Magistrado Díaz Eimil; ar. 1982\6355) al propietario — más bien, de acuerdo con la propia posición jurisprudencial relativa a la imputación del deber de urbanización y conservación habría que hablar de promotor-. En el mismo sentido se pronuncian las Ss.TS de 9 de mayo de 1985 (Ponente: Magistrado Diaz Eimil; ar. 1985\2903), 7 de noviembre de 1988 (Ponente: Magistrado Barrio Iglesias; ar. 198818786) y de 4 de marzo de 1989 (Ponente: Magistrado García Estartús; ar. 1989\1723).

\section{LA RECEPCIÓN; SUSCRIPCIÓN DEL ACTA DE RECEPCIÓN POR PARTE DEL PROMOTOR Y DE LA ADMINISTRACIÓN ACTUANTE}

Con anterioridad nos hemos referido ya a algunas cuestiones atinentes a este epígrafe como la posición jurisprudencial que legitima la diferencia entre la recepción provisional y la definitiva. Se trata ahora de poner de relieve ciertos requisitos formales determinantes de la validez del trámite de recepción. En efecto, como sabemos, la recepción es consecuencia de la entrega y puesta a disposición de las obras y servicios de urbanización que realiza el promotor de las obras y de la obligación que surge en tal sentido para la Administración por haber aprobado la obra. De esta forma, efectuada la verificación correspondiente si resulta positiva, si son aptas para el uso o servicio público previsto, sin que presenten vicios o defectos o si éstos no tienen la relevancia suficiente, se debe proceder a la formalización de la recepción, mediante la suscripción de la correspondiente acta por parte de la Administración municipal y del promotor. De esta forma, la Administración actuante toma posesión de las obras y servicios correspondientes, produciéndose su afectación al uso o servicio público y deben ser incluidos en el inventario general de bienes de acuerdo con la legislación de régimen local ${ }^{15}$.

\footnotetext{
misma perspectiva que $<<$ El Ayuntamiento comprobará en el plazo de tres meses que la obra realizada ha sido ejecutada conforme al proyecto de urbanización y, en su caso, notificará al solicitante la totalidad de las deficiencias observadas en relación con el contenido del proyecto citado, para que las subsane en el término que se señale >>, de tal forma que el [ap. c) del mismo precepto reglamentario] no se puede negar a recibir obras de urbanización con fundamento en defectos o vicios no señalados en la comprobación inicial y notificadas como tales al particular En el mismo sentido se pronuncian los arts. 142.2 LastS02, 136.2 LcmS98, 162. 2 LextrS01 y 163.2 LrgS01.
}

${ }^{15}$ En este sentido, el art. 135.2 LmadS01 dispone que $<<$ De la recepción de las obras se levantará acta, firmada por el funcionario técnico facultativo designado por el Alcalde, el facultativo 
En cualquier caso, es preciso destacar el valor que a los elementos solemnes y formales otorga la jurisprudencia contencioso-administrativa en este trámite. Recordemos en este sentido que la ya citada STS de 4 de mayo de 1982 impedía que la cesión de las obras y servicios de urbanización tuviera materialización por la simple voluntad u ofrecimiento del promotor sin ser aceptado formalmente por la Administración actuante. Pues bien, la recepción es para el TS un acto formal y expreso que no se produce ope legis por la mera aprobación del planeamiento. En efecto, la STS de 27 de junio de 1983 (Ponente: Magistrado: Gordillo García; Ar. 198313663) a partir de la ya conocida distinción entre los terrenos de cesión obligatoria y gratuita y las obras de urbanización afirma, en relación con la formalización de la recepción de las obras de urbanización, que $<<\ldots$ naturalmente habrá de documentarse, bien por medio de escritura notarial o a través del correspondiente documento administrativo, no sólo para dejar constancia cierta y fehaciente de la recepción definitiva por el Ayuntamiento de dichas obras de urbanización previa comprobación de que las ejecutadas cumplen los debidos requisitos, sino además, y entre otras razones que podrían citarse, porque es a través de dicha formalización como dichos viales y zonas ajardinadas pasan a integrarse en el dominio público municipal...>> . Por su parte, la STS de 1 de abril de 1985 (Ponente: Magistrado Rodríguez García; ar. 1985\1786) destaca que $<<$...el mantenimiento y conservación de las obras de urbanización no puede trasladarse a la Administración actuante hasta tanto no se ofrezca por su propietario la cesión de tales obras y aquélla, previas las oportunas comprobaciones, las acepte mediante un acto expreso de recepción...». La STS de 13 de marzo de 1987 (Ponente: Magistrado Brugera Manté; ar. 1987\3645) habla, por su parte, de la necesidad del otorgamiento de la escritura pública que solemnice la recepción definitiva. Y la STS de 21 de noviembre de 1989 reitera que la recepción $<<.$. tiene un acentuado carácter ritual, en el que previa la comprobación de su estado y circunstancias, lo que envuelve de ellas por los promotores a la Administración, poniéndolas a su disposición, se formaliza la correspondiente acta, acta que implica la conformidad con las realizadas y su aceptación y recepción. $>>$. Previamente el Tribunal Supremo se refería ya a la nece-

encargado de la dirección de las obras y la persona o entidad, pública o privada, responsable de la ejecución y el Alcalde o el Concejal en que delegue al efecto $>>$. En igual sentido se pronuncia el art. 136.4 (último párrafo) LcmS98. El art 162. 4 LextrS01 impone, por su parte, el deber de levantar un acta expresiva del resultado de todas las actuaciones dirigidas a la comprobación de las obras de urbanización ejecutadas para la recepción de dichas obras. En cualquier caso, levantada el acta, se debe remitir al Registro de la Propiedad certificación administrativa de ella a los efectos de la práctica de las inscripciones procedentes conforme a la legislación hipotecaria RbalS87 (arts 3.3 y 7.3), LmadS (art 135.6), (igual art 152.2 LcanS00). 
sidad de la existencia de $<<\ldots$ un acto expreso de recepción... >> , para que la misma se pudiera entender realizada. En el mismo sentido se expresan las Sentencias emitidas por el mismo órgano jurisdiccional con fecha de 11 de octubre de 1982 (Ponente: Magistrado Díaz Eimil; ar 1982\6355), 14 de abril y 28 de junio de 1983 (Ponentes: Martín del Burgo y Marchán y Martín Martín, respectivamente; ar $1983 \backslash 2088$ y 1983\3669), 1 de abril de 1985 (Ponente: Magistrado Rodríguez García; ar. 1985\1786), 13 de marzo y 3 de junio de 1987 (Ponentes: Magistrados Brugera Manté y ; ar. 1987\3645) y, 7 de noviembre de 1988 (Ponente: Magistrado Barrio Iglesias; ar. 198818786) o 21 de noviembre de 1989 (Ponente: Magistrado ).

En cualquier caso, es preciso destacar que la propia jurisprudencia contencioso-administrativa viene modulando desde hace años las exigencias de carácter formal analizadas y acepta la posibilidad de que la recepción de aquellas obras y servicios se produzca, válida y eficazmente, de forma tácita, es decir, como consecuencia de la conducta de la propia Administración actuante que con sus propios actos puede poner de manifiesto que la recepción de las obras efectivamente se ha producido, aunque no haya concurrido ningún acto expreso.

En efecto, con fundamento en la regulación del contrato administrativo de obra pública, la jurisprudencia viene admitiendo la posibilidad de una recepción tácita de las obras y servicios derivados de la urbanización, derivada de sus propios actos y que supone una cualificada excepción al principio de la formalidad del acto de recepción y aunque algún sector doctrinal ${ }^{16}$ ha dudado de su singularidad equiparando la esta clase de recepción a los supuestos de negligencia o pasividad municipal, es lo cierto, sin embargo, que el análisis de la jurisprudencia contencioso-administrativa no deja lugar a dudas. Al respecto es ilustrativa la STS de 29 de noviembre de 1993 (Ponente: Magistrado Barrio Iglesias; ar.199318796) que afirma que $<<\ldots$ aunque del art. 180 del mencionado Reglamento de Gestión Urbanística se infiera un acentuado carácter ritual de la entrega de las obras a la Administración y recepción de las mismas por ella, previa comprobación de su estado y circunstancias, lo que envuelve un previo ofrecimiento por los promotores, poniéndolas a su disposición, se formaliza la correspondiente acta, acta que supone la conformidad con las realizadas y su aceptación y recepción, también es posible una válida y eficaz por recepción y aceptación tácitas deducible de actos propios de la Administración vinculantes para la misma...>>. En concreto el Ayuntamiento en

\footnotetext{
${ }^{16}$ G. CORTÉs CORTÉs, La ejecución y recepción de las obras en las urbanizaciones de iniciativa particular; Edir Aranzadi; Pamplona 2001; p. 289.
} 
cuestión venía prestando a su cargo los servicios de alcantarillado y alumbrado. Desde la misma perspectiva, la STS de 21 de junio de 2001 (Ponente: Magistrado Sanz Bayón; ar. 2001\5800) afirma en relación con esta cuestión que $<<\ldots$ viene siendo doctrina mantenida por este Tribunal, la necesidad de un acto formal de aceptación de la cesión por parte de la Administración, para el nacimiento de su obligación de mantener y conservar las obras de urbanización, más no obstante, el actual criterio jurisprudencial del Tribunal Supremo, sobre tal cuestión, reflejado, entre otros, por las sentencias de 22 y 29 de noviembre de 1993, admite como posible, válida y eficaz la recepción y aceptación tácitas, deducible de actos propios de la Administración vinculantes para la misma >>, ejemplo de lo cual es, de acuerdo con dicho pronunciamiento judicial, la defensa del carácter público de las vías o la imposición de contribuciones especiales. Es preciso destacar que ya la STS de 13 de marzo de 1987 (Ponente: Magistrado Brugera Manté; ar. 1987\3645), había aceptado la recepción tácita por actos propios del Ayuntamiento como pueden ser la adopción de un acuerdo aprobando el pliego de condiciones necesarias para contratar la futura explotación de las instalaciones cedidas, un acuerdo facultando al alcalde para levantar el acta de recepción o el mero transcurso del periodo de garantía tras la recepción provisional sin formular observación, reclamación o reparo al estado de las obras objeto de cesión.

Más recientemente, la STS de 25 de enero de 2002 (Ponente: Magistrado Rodríguez-Zapata Pérez; ar. 2002/7329) tras reconocer el carácter formal del trámite analizado destaca que $<<\ldots$ es posible admitir excepcionalmente una recepción y aceptación tácita válida y eficaz que vincula a la Administración, cuando las obras se han realizado debidamente y existen actos propios de ésta que resultan concluyentes de tal recepción $>>$. En el mismo sentido se pronuncian las Ss. TS de 22 y 29 de noviembre (ar. $1993 \backslash 8796$ y $1993 \backslash 8796$, respectivamente) y 1 de febrero de 1999 (ar. 1999\921).

Por lo demás, es preciso destacar que el mismo efecto se produce materializada la recepción de la obra o servicio principal respecto de sus instalaciones o elementos accesorios. En este sentido la STS de 22 de noviembre de 1993 (Ponente: Magistrado García Ramos Iturralde; ar. 199318515) acepta la recepción tácita del sistema de ventilación de unos viales subterráneos (servicio público accesorio e inseparable en su funcionamiento de éstos que si fueron recibidos expresamente por el Ayuntamiento) de la denominada «Zona Comercial del Paseo de la Castellana de Madrid, AZCA» porque es $<<\ldots$ público y notorio que la urbanización del Centro Comercial AZCA viene siendo de uso público general e intenso desde hace años $>>$. 


\section{CONSECUENCIAS DE LA RECEPCIÓN; LA TRANSMISIÓN DEL DEBER DE CONSERVACIÓN}

La transmisión del deber de urbanización del promotor a la Administración actuante es el efecto más destacado de la correcta materialización del proceso de recepción ${ }^{17}$. Hasta ese momento, y de acuerdo con lo establecido en el artículo 67 del RGU, el deber de conservación de las obras de urbanización y el mantenimiento de las dotaciones e instalaciones de los correspondientes servicios corría a cargo del promotor que tiene la obligación de conservarlos en perfecto estado hasta el momento de su cesión a la Administración ${ }^{18}$. En este sentido se ha pronunciado reiterada y unánimemente la jurisprudencia contencioso-administrativa. Como ejemplo baste citar la STS de 2 de julio de 1991 (Ponente: Magistrado Pastor Lopez; ar. 199115726) afirma que <<...tanto los defectos de construcción de la red de alcantarillado y conducciones de aguas residuales y pluviales, como los de conexión de las de desagüe de determinadas viviendas construidas o promovidas por la demandante, que obedecen a deficiente realización inicial de las obras, (y de los que, por consiguiente, habría de responder en todo caso), e incluso los desperfectos cualificados que puedan derivar de la mala conservación de todos ellos, deben ser subsanados por la entidad urbanizadora, puesto que, según la misma expresamente reconoce y resulta del expediente administrativo, esta parte de las obras de urbanización y correspondientes redes de servicios de conducción de aguas residuales y pluviales no han sido formalmente recibidas por el Ayuntamiento mediante la correspondiente cesión de las mismas, según exige el artículo 180 del Reglamento de Gestión Urbanística, y ello en la forma prevista en el apartado 3 de dicho precepto, (formalizada mediante acta)... >>. Y, en el mismo sentido, se expresan las Ss. TS de 4 de mayo de 1982 (Magistrado: Gordillo García; ar. 1982/3109) en relación con los

\footnotetext{
${ }^{17}$ Igualmente, se debe proceder a la devolución de avales o garantías constituidos y el reintegro, en su caso, de los gastos anticipados. En este sentido, se pronuncian las SsTS 27 de abril de 1991 (Ponente: Magistrado Reyes Monterreal; ar. 199113524), 3 de enero de 1992 (Ponente: Magistrado Pastor López; ar. 19921704). De ahí que cuando la recepción definitiva de las obras de urbanización, respecto de las cuales ha sido exigido su constitución, no se verifique, al devolución no proceda (STS de 7 de marzo de 1995. Ponente: Magistrado Barrio Iglesias; ar. 1995\1950).

${ }^{18}$ En este sentido, resulta expresivo el art. 79.1 LvalS94, cuando afirma que $<<$ La conservación de las obras públicas municipales es responsabilidad del Ayuntamiento desde su recepción definitiva, siendo antes del urbanizador >>. El mismo efecto determinan los arts. 47 Rcat S97, 136.2 LcmS98, 156.1 LcantS 01 y 143.2 LastS02. Por su parte, el art. 8RbalS87 establece que $<<A$ partir de la ratificación del Acta por el Ayuntamiento Pleno, correrán a cargo de esté los gastos de conservación de la urbanización recibida, salvo en los supuestos de existencia de Entidades Urbanísticas de Colaboradoras de Conservación en cuyo caso los gastos de conservación correrán a cargo de la misma junta hasta su extinción>>.
} 
servicios de alumbrado público y red de riego y engarce de éstos con las redes generales, de 11 de octubre de 1982 (Magistrado: Díaz Eimil; ar. 1982 6355) en relación con la limpieza de los viales, de 2 de abril de 1984 (Ponente: Magistrado: Reyes Monterreal; ar. 1984\2553) y 2 de junio de 1988 (ponente: Magistrado Martín del Burgo y Marchán; ar. 198815074) en relación con el servicio de alumbrado público, de 28 de junio de 1983 (Ponente: Magistrado: Martín Martín; ar. 198313669) en relación con la reparación de la vía pública, STS de 31 de diciembre de 1986 (Ponente: Magistrado González Navarro), en relación con determinados servicios instalados en la vía pública (que se diferencian de esta última) y de 26 de septiembre de 1987 en relación con el sistema de alcantarillado, depuración y vertido Con carácter general, se pronuncian las SsTS de 18 de marzo de 1987, 29 de noviembre de 1993, 3 de mayo de 1994 (Ponente: Magistrado Esteban Álamo; ar. 1994/3592), de 18 de octubre de 2000 (Ponente: Magistrado Yagüe Gil; ar. 2000\10006). Por su parte, la STS de 7 de diciembre de 1981 (Magistrado: Díaz Eimil; ar. 1981\5368) califica ya tal obligación de conservación como personal y directa.

Esta posición jurisprudencial no tiene, sin embargo, un carácter absoluto. En efecto, resulta excepcionada cuando se trata de la prestación de los servicios municipales obligatorios. La prestación de estos servicios es siempre responsabilidad municipal y, por tanto, se haya materializado o no la correspondiente recepción de obras. En este sentido es expresiva la ya citada STS de 14 de abril de 1983 que con fundamento en la consideración de que $<<$...la diversidad de criterios, respecto una y otra materia, se deriva del paso de una administración de cosas (urbanismo), a una administración de personas (seguridad ciudadana y limpieza e higiene pública), puesto que, en la primera, juegan unos intereses materiales y hasta cuantificables, muy distintos a los que están en juego en la segundo, en la que la actuación de la Administración es obligada, bien como actuación de policía...; bien como prestadora de un servicio público (el de recogida de basuras)...>>, afirma que $<<$ Que a distinta solución hay que llegar en el tema de la prestación de los servicios de vigilancia y recogida de basuras en la zona en cuestión por tratarse de obligaciones de los Municipios, e incluso obligaciones mínimas ineludibles...que no pueden depender, pues su causa tiene otro origen del estado de la gestión urbanizadora respectiva, sino del simple hecho de que...exista una población necesitada de que se le preste seguridad y ese otro servicio de recogida de basuras, tan necesario para la higiene y para el ornato y limpieza de cualquier zona urbana...>>.

Por otra parte, es preciso destacar que en la praxis urbanística es relativamente frecuente que ante un requerimiento de la Administración actuan- 
te instando al promotor la ejecución de la urbanización, de determinadas obras o servicios o, simplemente, la subsanación de determinados defectos observados en éstos, aquel trate de liberarse de dichos deberes imputándolos, vía contractual, a los terceros adquirentes de los inmuebles resultantes de la actuación. En fundamento legal de esta práctica es el artículo 88 del TRLS $76^{19}$, en virtud del cual la transmisión de la propiedad lleva consigo la subrogación por parte de los nuevos adquirentes en los compromisos que hubiere contraído el anterior titular con la Corporación local en relación con la urbanización. En otras palabras, quedaban subrogados en los derechos y obligaciones del promotor dado que estás siguen a la cosa y no a la persona. Esta posición significaría, en definitiva, liberar a los promotores de las obligaciones que han contraído con la Administración actuante en relación con el cumplimiento de sus deberes de cesión obligatoria y de ejecución de las obras de urbanización ${ }^{20}$.

Por esta razón, la jurisprudencia contencioso-administrativa ha venido modulando tradicionalmente el alcance de dichas prácticas, negando la validez o, por lo menos, la eficacia en el seno de las relaciones administrativas a las mismas. Así, la STS 16 de diciembre de 1980 (Magistrado: Martín Martín; ar. 1980/5007), después de afirmar el relación con el deber de conservación - cierto alumbrado público - que <<...tal carga urbanísticamente corresponde a la entidad responsable de la Urbanización, al no haber sido aun entregados al Municipio los viales, servicios, etc., y ser de su cargo - bajo vigilancia e inspección del Ayuntamiento- la instalación o funcionamiento de los diferentes servicios...>>, destaca que no puede $<<\ldots$ enervarse tal obligación frente a la Administración por el hecho de haberse trasladado tales cargas, mediante estipulaciones en escrituras de venta de pisos a los moradores o copropietarios del barrio o urbanización resultante, por que tal situación, por sustitución del obligado, no es oponible a la Administración, porque independientemente de su licitud (la urbanización y la necesidad de la puesta a punto de los servicios básicos es cometido y carga del promotor-constructor, etc.) la sustitución o cambio del obligado a la prestación (deudor) aun dentro del

\footnotetext{
${ }^{19}$ De acuerdo con lo previsto en dicho precepto legal «La enajenación de fincas no modificará la situación de su titular en orden a las limitaciones y deberes instituidos por esta Ley o impuesta, en virtud de la misma, por los actos de ejecución de sus preceptos, y el adquirente quedará subrogado en el lugar y puesto del anterior propietario ante los compromisos que hubiere contraído con las Corporaciones públicas respecto a la urbanización y edificación».

${ }^{20}$ Desde esta perspectiva, resulta interesante la previsión contenida en el artículo citado de la Ley valenciana, de acuerdo con la cual, carece de toda validez todo pacto o disposición que pretenda trasladar la responsabilidad de la conservación de las obras públicas municipales a personas privadas o asociaciones de propietarios sin colaboración y control público sin condiciones o por tiempo indeterminado.
} 
régimen civil o común exigiría la conformidad del acreedor (art. 1205 del C.Civ) para ser válidas...>> . Más recientemente, la STS de 3 de mayo de 1994 (Ponente: Esteban Álamo; ar. 199413592), afirma que $<<\ldots$ si bien el artículo 88 del Texto Refundido de la Ley del Suelo de 9 abril 1976, establece un principio de subrogación, de suerte que en los supuestos de enajenación de fincas, el adquirente queda vinculado a la situación asumida por el anterior titular en orden a los compromisos contraídos con las Corporaciones Públicas respecto a la urbanización y edificación, sin embargo, tal garantía se establece no en favor del promotor de una urbanización sino de las Administraciones públicas, con la finalidad de asegurar la efectividad de los procesos de urbanización y edificación, no siendo, en consecuencia, hacedera la tesis del promotor recurrente aceptada por la Sala de instancia, de sustraerse a los compromisos contraídos con el Ayuntamiento demandado, tratando de desviarlos hacia los compradores de parcelas, ya que aquél, en cuanto a su calidad de promotor, asumió unas obligaciones determinadas entre las que figura precisamente la de urbanizar —artículo 5.3.2.d) de la Ley del Suelo-de las que debe responder frente a la Administración, subsistiendo tal obligación hasta su total satisfacción; ello con independencia de las estipulaciones establecidas entre el promotor y los adquirentes de parcelas y, en todo caso, sin perjuicio del referido principio de subrogación, que, repetimos, está establecido en beneficio de la Administración y no del promotor para asegurar la efectividad de los compromisos de urbanización y edificación contrariados por este último...>>. Otra cosa es, y así lo acepta el TS (Sentencia de 1 de abril de 2003 (Ponente: Sanz Bayón:; ar. 2003\2945), que tal subrogación venga impuesta por el correspondiente instrumento de planeamiento de cuya ejecución se trata. En tal caso, los compradores quedan subrogados en las responsabilidades contraídas por los promotores.

En cualquier caso, hay que destacar que tal conclusión no desvirtúa, sin embargo, la eventual existencia de un derecho de repetición del promotor contra los adquirentes de los inmuebles en virtud de las estipulaciones que ambas partes hayan contraído; estipulaciones cuya eficacia - que no validez- queda limitada al ámbito estrictamente privado de las partes. Así se pronuncia, entre otras, la STS de 3 mayo 1994 (Ponente: Magistrado Esteban Álamo; ar. 199413592). 


\section{Relación de abreviaturas utilizadas}

LandS - Ley 7/2002, de 17 de diciembre, de Ordenación Urbanística de Andalucía.

LastS - Ley 3/2002, de 19 de abril, de régimen del Suelo y Ordenación urbanística de Asturias.

RbalS - Decreto 38/1987, de 4 de junio, sobre recepción de urbanizaciones por los ayuntamientos de Baleares.

LcanS - Decreto Legislativo 1/2000, de 8 de mayo, por el que se aprueba el Texto Refundido de las Leyes de Ordenación del Territorio y Espacios Naturales de Canarias.

LcmS - Ley 2/1998, de 4 de junio, de Ordenación del Territorio y de la Actividad Urbanística de Castilla-La Mancha.

RcatS - Decreto 303/1997, de 25 de noviembre, por el que se aprueba el Reglamento, sobre medidas para facilitar la ejecución urbanística.

LextS - Ley 15/2001, de 14 de diciembre, del Suelo y Ordenación Territorial de Extremadura.

LrgS - Ley 10/1998, de 2 de julio, de Ordenación del Territorio y Urbanismo de La Rioja.

LmS - Ley 9/2001, de 17 de julio, del Suelo de Madrid.

LmurS - Ley 1/2001, de 24 de abril del suelo de la Región de Murcia.

LvalS - Ley 6/1994, de 15 de noviembre, reguladora de la Actividad Urbanística de Valencia. 